\title{
METACOGNIC̣ÃO E AS ATIVIDADES EXPERIMENTAIS EM FÍSICA: APROXIMAÇÕES TEÓRICAS
}

\begin{abstract}
RESUMO: O presente estudo refere-se a uma investigação teórica que teve o objetivo de estabelecer o conceito de metacognição e seus elementos, possíveis de serem potencializados nas atividades experimentais desenvolvidas na disciplina de Física no Ensino Médio. Devido à polissemia do termo na literatura, e diante dos resultados promissores de sua inserção no contexto educacional, julga-se pertinente proceder a uma identificação nas pesquisas internacionais, a fim de estabelecer os momentos em que essa forma de pensamento pode ser potencializada pelo professor, qualificando a aprendizagem. Como resultado, foram identificados seis elementos metacognitivos que, igualmente, se fazem presentes nas atividades experimentais e que, portanto, precisam ser entendidos como férteis, não somente em termos cognitivos, mas também para o estabelecimento de uma cultura de evocação do pensamento metacognitivo.
\end{abstract}

Palavras-chave: Pensamento Metacognitivo. Atividades Experimentais. Ensino de Física.

\section{METACOGNITION AND ACTIVITIES IN EXPERIMENTAL PHYSICS: THEORETICAL APPROACHES}

ABSTRACT: This study refers to a theoretical investigation to establish the concept of metacognition and its elements that could be leveraged in experimental activities carried out in Physics High school. Due to the different meanings of the term in literature and the promising results of its inclusion in the educational context, it is deemed appropriate to carry out an identification in international studies in order to establish when this thought may be enhanced by the teacher, qualifying learning. As a result, we identifies six metacognitive elements that are also present in the experimental activities and need to be understood as fertile, not only in cognitive terms, but also in the establishing a culture of evocation of metacognitive thinking.

Keywords: Metacognitive Thinking. Experimental Activities. Teaching Physics.
Cleci Werner da Rosa* José de Pinho Alves Filho**

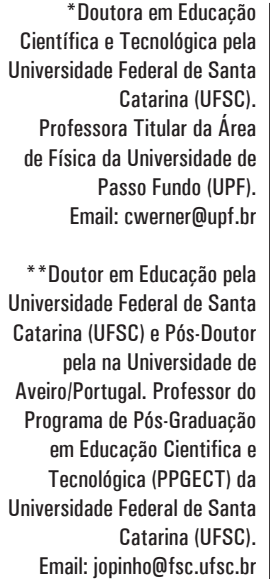

* Doutora em Educacão Científica e Tecnológica pela Universidade Federal de Santa Catarina (UFSC).

Professora Titular da Área de Física da Universidade de Passo Fundo (UPF). Email: cwerner@upf.br

* *Doutor em Educação pela Universidade Federal de Santa Catarina (UFSC) e Pós-Doutor pela na Universidade de Aveiro/Portugal. Professor do Programa de Pós-Graduação em Educação Cientifica e Tecnológica (PPGECT) da Universidade Federal de Santa Catarina (UFSC). Email: jopinho@fsc.ufsc.br 


\section{INTRODUÇÃO}

A metacognição tem sido apontada, na literatura, como alternativa para qualificar o processo de ensino-aprendizagem, atuando como mecanismo favorecedor da aprendizagem. Contudo, sua definição é polissêmica, o que pode ser observado pelos diferentes usos do termo pelas diversas áreas do conhecimento. Tal fato justifica a necessidade de que cada pesquisa esclareça a definição que faz do conceito, trazendo as implicações de sua compreensão. Ressalta-se que os entornos do conceito necessitam de estudos adaptativos, dependendo da aproximação desejada. No caso apresentado neste artigo, é feita uma aproximação com as atividades experimentais desenvolvidas com estudantes do Ensino Médio.

Para identificar os meandros inerentes à abordagem pretendida, foi realizada uma pesquisa do tipo bibliográfica junto à literatura especializada, a fim de fornecer subsídios teóricos aos professores para que considerem e potencializem o pensamento metacognitivo durante as atividades experimentais. Nessa perspectiva, nos estudos sobre memória feitos pelo psicólogo americano John Hurley Flavell, considerado o pioneiro na utilização do termo "metacognição", encontramos a aproximação inicialmente desejada, visualizando a sua pertinência. Porém, devido às especificidades das atividades experimentais, foi necessário ir além e ampliar o conceito de Flavell, sobretudo para detalhar como ocorrem os processos de autorregulação e de controle executivo das ações.

Assim, ao dirigir um olhar mais genérico para as proposições construtivistas em relação às atividades experimentais, é possível visualizar momentos em que esse tipo de pensamento se encontra presente, carecendo apenas de sua explicitação para que os estudantes a ele recorram e logrem de seus benefícios no processo de aprendizagem. Contudo, antes de se iniciar a descrição dos resultados deste estudo teórico, é imprescindível esclarecer duas situações: primeiro, foi adotada como referencial para as atividades experimentais a concepção construtivista, utilizando-se, para tanto, os conceitos de Pinho-Alves (2000), que por limitações textuais, não serão aqui discutidos; segundo, considera-se, de acordo com os estudos de Chi e colaboradores $(1982 ; 1989)$, que o pensamento metacognitivo é inerente ao ser humano, entretanto, sua utilização nem sempre é espontânea, necessitando ser explicitada pelo professor em sala de aula. Além disso, entende-se, conforme destacado pelos mesmos autores, que a evocação desse tipo de pensamento torna-se o diferencial entre os estudantes considerados experts e os novatos na resolução de problemas, por exemplo. (Chi et al., 1989)

Em síntese, este trabalho se refere a um estudo teórico com o objetivo de elucidar momentos das atividades experimentais em que o pensamento metacognitivo se faz presente e, portanto, pode ser potencializado pelo professor a fim de tornar-se explícito para os estudantes. De forma mais pontual, constitui-se como um referencial indicado para subsidiar futuras propostas metodológicas que incluam objetivos metacognitivos nas atividades experimentais. Trata-se, ainda, da elucidação do conceito de metacognição e seus elementos na busca pela inserção 
dessa forma de pensamento no processo de ensino-aprendizagem.

Para tanto, este artigo é estruturado em duas seções, além das considerações finais. Inicialmente, discute-se o processo de construção do conceito em Flavell e sua pertinência com as atividades experimentais; na continuidade, mencionam-se as operações executivas propostas por Ann Brown e sua relação com as atividades experimentais desenvolvidas em Física, estabelecendo, assim, o conceito de metacognição e seus entornos, conforme o objetivo do estudo.

\section{A CONTRIBUIC̣̃̃O DE FLAVELL}

$\mathrm{O}$ artigo "First discussant's comments: what is memory development the development of?" de Flavell (1971), é considerado como o marco introdutório do termo "metacognição". Nele o autor chama a atenção para a relação, até então inexplorada, entre o funcionamento da memória e o conhecimento que se tem sobre os processos de memorização. Tais questões sempre representaram a preocupação central das pesquisas de Flavell, nas quais o autor demonstra que, com o avançar da idade, as crianças melhoram sua capacidade de realizar tarefas que envolvam a memória seletiva, por exemplo. À medida que crescem, os estudantes aperfeiçoam suas capacidades para estimar o tempo que levam para memorizar uma lista de palavras ou uma sequência de números. Tais estudos permitiram a Flavell introduzir o termo "metacognição" para designar o conhecimento que o sujeito tem quanto à sua cognição. Em outras palavras, constitui o pensar sobre o pensar, enfatizando a importância da tomada de consciência do indivíduo durante a realização de uma tarefa.

Posteriormente, Flavell infere que a metacognição se vincula às experiências do conhecimento metacognitivo: as primeiras (experiências), referindo-se a qualquer consciência cognitiva e afetiva que acompanha e pertence a determinada troca intelectual; o segundo (conhecimento), entendido como segmento do mundo de conhecimentos adquiridos e acumulados nos indivíduos e que considera as pessoas como seus agentes construtores, com a diversidade cognitiva nelas existente.

Para situar essa compreensão inicial de Flavell sobre metacognição, ainda por ser ampliada em estudos futuros, acredita-se que esta estaria limitada à tomada de consciência do estudante sobre seus conhecimentos, sendo, pois, influenciada por aspectos afetivos e por suas experiências, tudo vinculado à sua memória. Assim, nessa primeira tentativa, o autor mostra que a metacognição, já determinada como o conhecimento do conhecimento (conhecimento metacognitivo), estaria atrelada à reflexão do estudante sobre seus conhecimentos e ao seu sentimento em relação à atividade e à estratégia que deverá utilizar (decorrente de suas experiências nessa área).

Identificando esse primeiro momento do conceito com as atividades experimentais, tem-se sua relação com as manifestações dos estudantes, de forma positiva ou negativa, diante da proposta do professor, identificando em sua memória experiências passadas. São manifestações dos estudantes do tipo "sei fazer"; "entendo 
bem este assunto"; "gosto de Física"; "tenho facilidade em manusear este equipamento"; ou, ao contrário, "sou um desastre em aulas práticas"; "na última atividade não entendi nada", etc. O sentimento produzido por experiências anteriores é fundamental para que os estudantes ativem, em seus pensamentos, os conhecimentos necessários à atividade proposta que, consequentemente, tornam-se essenciais ao êxito de sua execução. Esse é o primeiro aspecto a ser considerado em uma atividade experimental que está relacionado à metacognição: produzir um sentimento em relação a ela. Esse sentimento vai definir os comportamentos dos estudantes diante da atividade experimental antes mesmo de ela ser iniciada.

Essas experiências metacognitivas estão, na acepção de Flavell, relacionadas ao conhecimento metacognitivo que, por sua vez, é entendido como o responsável pela tomada de consciência do estudante sobre o que sabe. São conhecimentos e crenças que ele acumulou por meio de experiências e que armazenou na memória em longo prazo. Desse modo, inferir que sabe algo, ou julgar o que é bom em uma atividade experimental, representa uma evocação de pensamento metacognitivo, pois são manifestações decorrentes de experiências do conhecimento metacognitivo que o estudante expressa a partir de sua vivência. Nas atividades experimentais, por seu caráter mais livre, mais dinâmico, essa forma de pensamento é facilmente observável nos estudantes, podendo ser potencializada como forma de ativar seus conhecimentos em prol da identificação com os saberes envolvidos no estudo. Em termos de benefícios para a aprendizagem, Flavell destaca que, no caso da ativação da memória, a identificação do que o estudante já conhece e o sentimento que ele tem em relação a si próprio são mecanismos essenciais, pois mobilizam toda a estrutura de pensamento. A identificação de que tem dificuldades num determinado assunto pode levar o estudante a prestar mais atenção nas explicações do professor, a buscar o conteúdo em livros didáticos ou até mesmo levá-lo a se aproximar de outros estudantes com mais facilidade de domínio do tema.

Entretanto, a possibilidade de que esses conhecimentos metacognitivos sejam ativados no sujeito, atuando na melhoria da capacidade de memória ou extensivamente na melhoria da aprendizagem, leva Flavell a deduzir que eles precisam ser ativados por mecanismos que os impulsionem, referindo-se às exigências da tarefa. Mais especificamente, ao investigar a dificuldade que os estudantes apresentam para generalizar e transferir o que aprendem a novas situações, diferentes daquelas que originaram suas aprendizagens, Flavell formulou a hipótese de que os recursos cognitivos dos sujeitos não são espontâneos, mas surgem à medida que eles têm necessidade de solucionar tarefas ou problemas concretos, escolhendo as estratégias pertinentes a cada situação. Dessa maneira, o autor conclui que para o sujeito recorrer a seus conhecimentos como forma de obter êxito em sua aprendizagem (ou recuperação da memória), é necessário que a situação exija dele, acrescentando ao entendimento anterior a ação a ser executada e a capacidade do sujeito de regular essa ação.

Nas atividades experimentais, essa ativação do pensamento se encontra associada às exigências da atividade, ou seja, ao seu objetivo cognitivo. Portanto, o 
processo de ativar o pensamento é proporcionado pelo "desafio" da atividade experimental a ser executada e por aquilo que conduzirá o estudante a sua execução. Associando ao exposto por Flavell, pode-se afirmar que o objetivo da atividade experimental pode atuar como estímulo à evocação do conhecimento, à identificação pelo estudante do que ele sabe ou julga saber de si mesmo em relação ao conteúdo ou à execução da atividade, assim como pode incitar seus sentimentos em relação à tarefa. Logo, o objetivo cognitivo pode ser o ativador do pensamento metacognitivo em uma atividade experimental. Como decorrência desse pensamento, em 1976 Flavell ampliou a sua definição, incluindo, explicitamente, a autorregulação. Nesse novo entendimento, ele acrescenta a necessidade de que o sujeito recorra a sua estrutura cognitiva para monitorar e supervisionar seus próprios conhecimentos, não apenas para identificá-los. Amplia-se, assim, o termo "metacognição", conforme explicitado no artigo "Metacognitive aspects of problem solving":

\begin{abstract}
"Metacognição" se refere ao conhecimento que se tem dos próprios processos e produtos cognitivos ou de qualquer outro assunto relacionado a eles, por exemplo, as propriedades relevantes para a aprendizagem de informações ou dados. [...]. A metacognição se refere, entre outras coisas, à avaliação ativa e consequente regulação e orquestração desses processos em função dos objetivos e dados cognitivos sobre o que se quer e, normalmente, a serviço de alguma meta ou objetivo concreto. (FLAVELL, 1976, p. 232, destaque do autor, tradução nossa).
\end{abstract}

Com a nova definição, a metacognição passa a englobar dois aspectos: o conhecimento do próprio conhecimento e o controle executivo e autorregulador das ações. O primeiro vincula-se aos conhecimentos que os indivíduos possuem sobre seus recursos cognitivos e à relação entre eles. O segundo relaciona-se ao controle e à regulação dos processos cognitivos, ou seja, à capacidade que os indivíduos apresentam de planejar estratégias de ação a fim de atingir um determinado objetivo, bem como dos ajustamentos necessários para que isso se concretize.

O detalhamento de como o conhecimento metacognitivo pode atuar como favorecedor da ativação da memória é inferido por Flavell no artigo publicado em 1977, em colaboração com Wellman, intitulado "Metamemory". Nesse artigo, os autores identificam dois aspectos básicos que interferem na execução de uma atividade (recuperação da memória): a sensibilidade e o conhecimento de três variáveis - pessoa, tarefa e estratégia. Conforme as palavras dos autores:

\footnotetext{
Primeiro, algumas situações requeridas para exigir esforços relacionados à memória e outras que não [sensibilidade]. Segundo, o desempenho em uma situação de memória ou tarefa é influenciado por um número de fatores cuja natureza uma pessoa deveria saber. Nós temos três classes principais de tais fatores [variáveis]: (1) características relevantes de memória da própria pessoa [variável pessoa]; (2) características relevantes de memória para a tarefa [variável tarefa]; (3) estratégias potenciais de emprego/uso [variável estratégia]. (FLAVELL; WELLMAN, 1977, p. 5, tradução nossa).
} 
Nessa acepção, tem-se por "sensibilidade" a capacidade de o indivíduo decidir sobre a necessidade ou não de utilizar estratégias para desenvolver determinada atividade. Essa decisão se refere à realização das atividades espontâneas (aquelas que apresentam um objetivo, mas não são determinadas por instrução específica) e das atividades induzidas (aquelas que decorrem de instruções que levam à adoção de estratégias para se chegar ao objetivo). É a tomada de decisão do estudante sobre recorrer ou não ao pensamento metacognitivo. Se perceber que o melhor é recorrer, este deverá contemplar aspectos relacionados às variáveis do conhecimento metacognitivo que precisam estar presentes para atingir o objetivo pretendido.

As variáveis da pessoa, da tarefa e da estratégia, assim como de suas relações, resultam das crenças do indivíduo como ser cognitivo; é o conhecimento que as pessoas têm sobre elas mesmas, o qual afeta o seu rendimento na realização de suas tarefas (aprendizagem). Esse conhecimento é estabelecido por meio da tomada de consciência das próprias variáveis mencionadas, bem como pelo modo como interagem e influenciam no alcance do objetivo cognitivo. Tais variáveis encontram-se próximas das atividades experimentais, podendo ser potencializadas por ela, conforme se descreve a seguir.

O conhecimento das variáveis da pessoa (ou pessoais) é representado pelas convicções que os indivíduos apresentam sobre si mesmos e em comparação com os outros. É o momento em que identificam como funciona seu pensamento, como se processam as informações que lhes são fornecidas, caracterizando-se pela identificação de suas crenças, mitos e conhecimentos, assim como pela identificação dessas características no outro. Segundo Flavell e Wellman (1977), uma das tarefas do sujeito consiste em desenvolver um "autoconceito mnemônico", "autoconceito cognitivo", que com o tempo deverá ser cada vez mais elaborado. Isso significa que num processo evolutivo, o sujeito deverá ser capaz, cada vez mais, de entender suas capacidades e suas limitações, pondo-as em prática a fim de realizar suas tarefas com êxito.

Esse conhecimento sobre si mesmo pode ser de três tipos: universal, intraindividual e interindividual. Os conhecimentos universais estão relacionados àquilo que os indivíduos apresentam sobre como é ou como julgam ser a sua mente. Segundo Flavell, Miller e Miller (1999), esse é o mais interessante dos três tipos, pois permite que sejam reconhecidas características presentes no sujeito e no outro que estão presentes na mente humana de modo geral. Reconhecer que as pessoas podem não recordar um fato num primeiro momento, mas que talvez consigam recordá-lo futuramente é um exemplo de conhecimento universal, pois essa característica pertence a todos os indivíduos, inclusive ao próprio sujeito.

Por sua vez, os intraindividuais representam as crenças, os mitos que as pessoas têm sobre si mesmas, como a identificação, por parte do aluno, de que é preciso anotar tudo o que o professor fala para compreender o assunto; de que é necessário manusear o equipamento didático em uma atividade experimental para entender seu funcionamento; de que é preciso escrever todos os passos que estão seguindo para entendê-lo, etc. Por fim, os conhecimentos interindividuais dizem 
respeito às comparações estabelecidas pelos sujeitos entre si, tais como: "ele entende melhor a explicação do professor que eu"; "sou bom em cálculos"; "ele é mais habilidoso que eu com este equipamento", etc.

No processo ensino-aprendizagem essa variável se manifesta na identificação, pelo estudante, de características pessoais, podendo estabelecê-las em comparação ao outro, conforme mencionado. Isso inclui os conhecimentos e informações sobre determinados conteúdos (em Física, por exemplo), a amplitude e a maneira como o estudante se relaciona com esses saberes. É um feedback da estrutura interna de pensamento do estudante. Entre os aspectos que proporcionam essa retomada nos saberes para deles fazer uso mediante uma situação de aprendizagem está a motivação, atuando como propulsora desse movimento interno e do pensamento metacognitivo.

Quando um estudante, ao iniciar uma atividade experimental sobre o movimento de rotação e translação da Terra, por exemplo, julga que será complexo entendê-lo, pois apresenta dificuldades em compreender movimentos relativos, mas pondera que se realizar o estudo com um colega que considera ser mais competente no assunto, poderá compreender melhor esses movimentos, ele está manifestando pensamento metacognitivo em termos da variável pessoa. Ou ainda quando, nesse mesmo estudo, ele manifesta não ter claro o fato de a Terra estar em movimento, mas reconhece que isso resulta da falta de conhecimentos nessa área, isso, igualmente, pode desencadear um comportamento de pensamento metacognitivo. Destaca-se, assim, a importância de o professor propor nas atividades experimentais momentos para que os estudantes identifiquem seus conhecimentos prévios e suas características pessoais em relação a esse conhecimento, buscando alternativas para suprir possíveis deficiências. Além disso, a natureza e as exigências da atividade experimental também influenciam nesse movimento de retomar os saberes, o que é caracterizado pela variável tarefa.

O conhecimento das variáveis da tarefa está relacionado a suas demandas, representadas pela abrangência, extensão e exigências envolvidas na sua realização. É a identificação, pelos sujeitos, das características da tarefa em pauta, tanto em termos do que ela é, como do que envolve. Nas pesquisas sobre memória, Flavell e Wellman (1977) mostram que há tarefas mais fáceis de serem lembradas que outras e que algumas demandam mais tempo e mais elementos e, por isso, são tidas como mais difíceis. Além disso, o tipo e a estrutura do material envolvido também influenciam nesse processo de recordar.

Flavell, Miller e Miller (1999) assinalam que a variável tarefa encontra-se subdividida em duas: uma tem a ver com a natureza da informação que o sujeito encontra e processa em qualquer atividade cognitiva, por exemplo, acontece quando o estudante sabe que tendo informações escassas sobre uma tarefa, terá maiores chances de compreendê-la equivocamente; o outro tipo vincula-se à natureza da exigência da tarefa, de que é exemplo o fato de um estudante saber que é mais fácil recordar a ideia geral de uma história do que suas palavras exatas.

No processo ensino-aprendizagem, ao se deparar com uma tarefa, o estu- 
dante recorre a seus pensamentos verificando o grau de dificuldade dela, podendo se sentir incapaz de realizá-la ou desmotivado para tal; ou, o contrário, verificar que já realizou algo semelhante ou reconhecer os conhecimentos envolvidos, sentindo-se capaz, motivado para a tarefa. Todo esse movimento é um pensar metacognitivo que poderá levá-lo a lograr êxito na tarefa. Por isso a importância de o professor não propor tarefas demasiadamente distantes da capacidade de seus estudantes, pois isso poderá provocar sentimentos de que ele não é capaz de realizá-las, de aprender com elas, e que apesar de decorrentes de seu pensamento metacognitivo, tais tarefas poderão não contribuir para a aprendizagem.

Em termos das atividades experimentais, a variável tarefa mostra-se relacionada ao momento em que o estudante se dá conta do tipo de tarefa e dos conhecimentos envolvidos e necessários para a sua execução. Isso se encontra diretamente vinculado ao tipo de tarefa (natureza experimental da atividade) e aos objetivos a serem atingidos. Portanto, quando um estudante se depara com uma atividade experimental que exige dele algo diferente dos estudos teóricos, por exemplo, poderá ativar seus pensamentos atuando de forma positiva ou negativa para a aprendizagem. Como exemplo, cita-se o estudo para verificar a velocidade constante de um móvel, no qual é preciso que o estudante perceba as limitações do modelo teórico proposto pelo professor diante da situação real presente na atividade experimental. Esse comportamento de comparar situações decorre de um movimento de evocação do pensamento metacognitivo, cujo passo seguinte será identificar a estratégia para realizar essa atividade, o que envolve os conhecimentos relacionados à variável estratégia.

Os conhecimentos das variáveis relacionadas à estratégia vinculam-se ao "quando", "onde", "como" e "por que" aplicar determinadas estratégias. É o momento em que o sujeito se questiona sobre o que precisa ser feito e quais os caminhos a serem seguidos para atingir o objetivo. Flavell, Miller e Miller (1999) afirmam que essa variável se encontra relacionada à identificação, pelos estudantes, de quais estratégias são mais adequadas para chegar a determinados resultados cognitivos. São as estratégias de recuperação ou armazenamento da informação na memória, ou são aquelas traçadas pelos estudantes para efetivar suas aprendizagens.

No processo ensino-aprendizagem, a identificação da estratégia representa o reconhecimento, pelo estudante, dos caminhos para aprender, bem como a identificação de por que escolher aquele caminho. Por exemplo, ao se organizar para estudar Física, ele percebe que precisa se estruturar de forma diferente do que quando vai estudar História; ou na identificação pessoal de que para aprender a resolver os problemas de Física, a melhor estratégia é iniciar pela leitura atenta do problema, identificando o conhecimento envolvido para, em seguida, iniciar o processo de solução.

Nas atividades experimentais, essa variável se encontra relacionada ao momento em que os estudantes percebem que a realização de uma atividade requer uma estratégia de ação diferente de outra, identificando a mais adequada. Por exemplo, ao realizar uma atividade experimental envolvendo processos de transferência de 
calor entre um corpo aquecido e o meio ambiente, o estudante conclui que nela são necessários cuidados operacionais diferentes dos aplicados no estudo da constante elástica da mola. Essa comparação entre estratégias conduz o estudante a retomar seus conhecimentos, podendo levá-lo a ativar seu pensamento metacognitivo.

O reconhecimento, pelos estudantes, da necessidade de estratégias, e das mais adequadas, para cada atividade experimental reflete-se na tomada de consciência sobre seus conhecimentos, remetendo-os a pensamentos metacognitivos. Entretanto, nem sempre a identificação de uma estratégia resulta de um pensamento metacognitivo, pois ela pode estar relacionada apenas aos caminhos a serem executados, sem a identificação das razões que levam o estudante a escolher tais caminhos. O uso de uma estratégia pode resultar, por exemplo, de um processo mecânico no qual existe a consciência de que algo acontece de determinada maneira, mas não se sabe o porquê. A estratégia referida aqui envolve não apenas traçar passos, mas saber por que esses passos são os escolhidos.

Flavell (1979) lembra que o conhecimento metacognitivo resulta da integração dessas variáveis que, por sua vez, não são independentes, mas compõem um conjunto no qual estão interligadas, constituindo o conhecimento do conhecimento que o sujeito precisa ter para desenvolver suas atividades (atingir objetivos) de forma mais eficaz. Flavell, Miller e Miller exemplificam a combinação entre as variáveis, assinalando: “[...] você sem dúvida selecionaria uma estratégia de preparação diferente se tivesse que fazer uma palestra sobre algum tópico do que se somente precisasse assistir a uma palestra dada por outra pessoa" (1999, p. 127).

Sendo mais explícito em termos dessas variáveis nas atividades experimentais, pode-se dizer que elas se mostram conjuntas quando um estudante consegue ter clareza de suas características pessoais, do tipo de atividade a ser desenvolvida, dos conhecimentos de que precisa para desenvolvê-la (tanto dos conteúdos específicos como da atividade em si) e da estratégia a ser utilizada para realizá-la. Esse conjunto de ações de identificação pessoal do estudante resulta de sua evocação metacognitiva atuando positivamente no processo de construção do conhecimento. Evidentemente, apenas reconhecer aspectos como os mencionados para as variáveis pessoa, tarefa e estratégia não repercute em aprendizagem. É necessário que, ao identificá-las, de forma positiva ou negativa, o estudante mobilize suas estruturas cognitivas direcionando suas ações para atingir aos propósitos do estudo ou da tarefa. Portanto, não basta identificar ou não a tarefa para lograr os benéficos da evocação do pensamento metacognitivo; é preciso ir além, pondo em movimento toda a estrutura cognitiva.

Os benefícios decorrem do conjunto dessas variáveis e de sua inter-relação, que é estimulada pela exigência da execução da tarefa (objetivo cognitivo). De posse da identificação de seus conhecimentos pessoais referentes à atividade, ao tipo de atividade e da estratégia a ser utilizada, o estudante traçaria seu plano de ação (ou do grupo) a fim de atingir seus objetivos cognitivos.

Mesmo que essas variáveis tenham sido estudadas, inicialmente, para 
questões vinculadas ao armazenamento e à recuperação da memória, sua pertinência às atividades experimentais é evidente porque tais atividades podem ser potencializadas pela ativação do conhecimento metacognitivo, inclusive abrangendo o fator de ativação desse conhecimento (objetivo cognitivo).

O reconhecimento das experiências anteriores e a identificação do conhecimento existente na estrutura cognitiva do estudante são mecanismos internos de origem metacognitiva que influenciam na construção dos novos saberes, fornecendo condições para que o estudante identifique como está procedendo para construí-los. Essa ativação interna, seja das experiências, seja do conhecimento, é impulsionada pelos objetivos e pelas ações de âmbito cognitivo, cujo conjunto suscita à evocação do pensamento metacognitivo que foi denominado por Flavell (1979) como "Modelo de monitoração cognitiva".

Flavell, em 1979, no artigo "Metacognition e cognitive monitoring: a new area of cognitive - developmental inquiry", propôs de forma mais geral que a regulação do pensamento metacognitivo ocorre pela ação e interação de quatro aspectos: conhecimento metacognitivo, experiências metacognitivas, objetivos cognitivos e ações cognitivas. Logo, para que um sujeito (estudante) ative seu pensamento metacognitivo, quatro aspectos devem estar conectados, fornecendo os substratos necessários a essa ativação. Por conhecimento metacognitivo Flavell reitera sua compreensão inicial: é o conhecimento que o sujeito tem sobre si próprio no que se refere às variáveis pessoa, tarefa e estratégia, e também é a maneira como essas variáveis interferem no resultado da cognição. Portanto, a indicação "sou bom em Física e ele é melhor em Português" é um exemplo do conhecimento metacognitivo. Flavell indica que esse conhecimento metacognitivo consiste, primeiramente, no conhecimento ou na opinião sobre que fatores ou variáveis agem e interagem e de que maneira afetam o curso e o resultado cognitivo.

Quanto às experiências metacognitivas, Flavell destaca que as impressões ou percepções conscientes podem ocorrer antes, durante ou após a realização de uma tarefa, sempre que o sujeito vivenciar alguma dificuldade ou falta de compreensão de algo de grande importância para ele. Pode-se, então, chegar aos meios de sua superação. As experiências metacognitivas são conscientes, cognitivas e afetivas; podem ser breves ou longas, simples ou complexas, em termos de conteúdos; também podem servir para uma variedade de funções úteis nas iniciativas cognitivas. Como exemplo, menciona-se o fato de proceder a ações adaptativas no momento em que se percebe que não se está entendendo o que se lê (reler, repensar o que já estava ou julgava que estivesse entendido, etc.). (FLAVELL; MILLER; MILLER, 1999).

Para Flavell (1979), tanto o conhecimento metacognitivo como as experiências metacognitivas estão interligados, fazendo parte de um conjunto interdependente, na medida em que permitem interpretar tais experiências e agir sobre elas. É o que na definição de 1976 ele identifica como o conbecimento do conbecimento.

Já por objetivos cognitivos Flavell designa os implícitos ou explícitos, que impulsionam e ativam as estruturas cognitivas. No âmbito da sala de aula, podem ser impostos pelo professor ou selecionados pelo próprio aprendiz. Como exemplo, 
tem-se que os objetivos presentes nas atividades experimentais, normalmente definidos pelo professor, seriam o mecanismo ativador das estruturas cognitivas dos estudantes, os quais impulsionam e movem a execução da ação.

As ações cognitivas utilizadas para potencializar e avaliar o progresso cognitivo podem ser de dois tipos: as que estão a serviço do monitoramento (avaliação da situação), buscando produzir experiências metacognitivas e resultados cognitivos, e as que visam atingir um objetivo cognitivo, buscando, igualmente, resultados cognitivos. A diferença entre as duas está nos propósitos a que se destinam: na primeira, o estudante busca desenvolver uma atividade experimental, por exemplo, e para isso traça ações a fim de avaliar se está se conduzindo bem, como está procedendo, se fazendo de tal forma vai atingir o objetivo; na segunda, ele traça as ações e busca avaliar o procedimento em termos do resultado obtido, sem se preocupar com o processo que o levou a chegar a esse resultado.

Os objetivos cognitivos e as ações ativam o conhecimento e as experiências metacognitivas, constituindo o pensamento metacognitivo que, quando presente, tende a possibilitar ao estudante lograr êxito em sua tarefa. Nessa interpretação, fica claro que Flavell mescla cognição e metacognição em sua definição, demonstrando que tais conceitos estão intimamente relacionados. O autor mostra que a metacognição, além de ser um dos aspectos constituintes do desenvolvimento cognitivo, é encarregada da constituição da cognição em si, isto é, metacognição e cognição são indissociáveis, pois cognição envolve metacognição. Para exemplificar, Flavell (1987) descreve a presença da metacognição na velocidade de processamento da informação. É o sistema metacognitivo que monitora as alterações na velocidade desse processo, que são realizadas durante a execução de uma tarefa, ou seja, o modo como o estudante executa uma atividade experimental, por exemplo, e o quão significativa é a sua aprendizagem relativa a essa atividade, encontram-se associados à forma como os mecanismos metacognitivos são ativados. Ainda para Flavell (1987), o desenvolvimento da metacognição apresenta-se limitado caso o estudante não detenha conhecimentos específicos, o que permite inferir que a associação da metacognição com as atividades experimentais precisam estar apoiadas em conteúdos específicos de Física, sem os quais não há como, nem por que, ativar o pensamento metacognitivo.

Por fim, Flavell atribui ao processo metacognitivo uma capacidade autorreguladora que age sobre o sistema cognitivo. Essa autorregulação decorre da identificação, pelo sujeito, dos seus conhecimentos, tanto em termos do conteúdo específico como de sua capacidade para adquirir, recuperar e manipular esse conhecimento. Nas atividades experimentais, isso se revela na perspectiva de que o estudante, durante o desenvolvimento de uma atividade experimental, orquestre suas ações baseando-se na identificação de seus conhecimentos. Tal ampliação mostra que a definição mais adequada para a metacognição, na acepção de Flavell, envolve tanto o conhecimento que o sujeito tem sobre seus conhecimentos (eventos cognitivos) como o modo pelo qual ele regula e monitora os processos da cognição.

A descrição de como poderá ocorrer o processo de monitoração inclui 
planejar, revisar e avaliar o progresso cognitivo. Contudo, a especificação de como isso se traduz em operações de execução, pelo sujeito, no desenvolvimento de uma atividade específica é mais bem explicitada nos estudos de Ann Brown. Tais estudos, desenvolvidos a partir das pesquisas em leitura e interpretação de textos, encontram-se próximos das ações realizadas no desenvolvimento das atividades experimentais. Por isso, são tomados como referência para especificar o componente metacognitivo referente ao controle executivo e autorregulador das ações, conforme se apresenta na continuidade.

\section{AMPLIAC̣ÃO DO CONTROLE EXECUTIVO}

A psicóloga Ann Brown, referenciada nas pesquisas de Flavell, utilizou-se do entendimento do autor sobre o termo "metacognição", acrescentando o detalhamento do processo de controle executivo e autorregulador. Brown (1978), assim como Flavell, entende que a metacognição não se refere apenas ao conhecimento do conhecimento, mas também envolve a capacidade do sujeito de monitorar, autorregular e elaborar estratégias para potencializar sua aprendizagem. Com base nisso, a autora e colaboradores estruturam suas pesquisas valorizando as estratégias de aprendizagem metacognitivas, mostrando que com o passar do tempo há um significativo aumento no controle dessas estratégias e de outros processos cognitivos, de modo a orquestrá-los eficientemente.

Os estudos de Brown enfatizam a metacognição como a consciência do próprio conhecimento ou a compreensão desse conhecimento, concebendo que o sujeito, ao compreender esse conhecimento, poderá utilizá-lo adequadamente na realização das atividades. Para Brown (1977), a metacognição envolve autoconsciência, ou seja, implica na tomada de consciência sobre se se sabe, o que se sabe e o que não se sabe. A distinção em relação aos estudos de Flavell é que, para Brown, o controle executivo da tarefa representa um mecanismo autorregulatório, constituído por operações relacionadas aos mecanismos de ação do sujeito, ao passo que, para Flavell, a autorregulação se relaciona a um mecanismo de monitoração do próprio conhecimento. Portanto, segundo Brown, deve-se associar metacognição, num primeiro momento, ao conhecimento sobre os recursos e estratégias mais adequadas à efetivação de determinada tarefa - o conhecimento do conhecimento; em outro, ao controle executivo, que abrange mecanismos autorregulatórios quando da realização da tarefa, como a planificação, a monitoração e a avaliação das realizações cognitivas. Ambos estão inter-relacionados, cada um alimentando o outro, embora possam ser facilmente identificáveis.

De acordo com Brown (1987), o conhecimento do conhecimento é estável, verbalizável e falível, já que quem conhece algo sobre sua cognição o conhecerá sempre, podendo, inclusive, estar equivocado; por outro lado, o controle executivo e autorregulador mostra-se instável e nem sempre passível da verbalização, dependendo da situação e da tarefa. Portanto, somente quando o sujeito regula ou 
monitora as tarefas de cognição é que pode tirar benefício dos fracassos, deixando de lado as estratégias inadequadas. Pode-se dizer que, segundo a autora, não basta que o estudante tome consciência dos seus conhecimentos; é preciso que ele os operacionalize (atividade experimental, por exemplo), pois somente assim saberá se sabe o que julga saber.

Direcionando seus estudos para a leitura e interpretação de textos, Brown (1978) exemplifica mencionando a importância de serem identificados no texto o objetivo e seus aspectos relevantes; de se concentrar a atenção nos tópicos principais; de se avaliar a qualidade da compreensão efetivada; de se verificar se os objetivos estão sendo alcançados; de promover as devidas correções quando existirem falhas na compreensão; de observar o andamento da leitura e corrigi-la quando houver distração, divagações ou interrupções. Tais aspectos pertencem ao mecanismo de controle executivo e autorregulador e podem ser sintetizados pelas operações de planificação, monitoração e avaliação. A seguir, discute-se cada uma das operações mencionadas, visualizando-as no contexto das atividades experimentais.

A planificação é a responsável pela previsão de etapas e escolha de estratégias em relação ao objetivo pretendido, o que supõe fixar metas sobre como proceder para realizar a ação. Brown (1987) menciona que o planejamento somente poderá ocorrer à medida que o sujeito conhecer o problema em sua forma global e iniciar a busca pela solução. O planejamento inicial é relativamente completo, hierárquico e sujeito a refinamentos em seus níveis mais baixos. Entretanto, em qualquer ponto do planejamento as decisões do sujeito oferecem oportunidades para o desenvolvimento do plano, consistindo em ações independentes e decorrentes de decisões influenciadas por seu conhecimento. A decisão tomada por ele durante a planificação das ações o permite interagir com os dados disponíveis, podendo influenciar ou ser influenciado por estes. Brown (1987, p. 87) afirma que um bom planificador faz planos e toma decisões com base nesses planejamentos, que são influenciados por seus conhecimentos de mundo.

Em termos da aprendizagem escolar, essa operação pode ser identificada com a organização de materiais para estudar ou a elaboração de um questionário referente ao tema em estudo com objetivo de guiar o estudante. O que em Flavell estaria incluso no conhecimento metacognitivo, mais especificamente nas estratégias a serem adotadas para lograr êxito na tarefa, em Brown, por se referir à etapa de execução da ação, pressupõe traçar estratégias específicas da ação. Nas atividades experimentais, essa planificação é observada no momento em que o estudante decide, sozinho ou em seu grupo de trabalho, sobre a forma de executar a tarefa, os meios e equipamentos necessários para tal, tudo de acordo com os conhecimentos já identificados em sua estrutura cognitiva e de acordo com o objetivo a ser atingido. Refere-se à identificação do que deverá ser realizado, ao ponto onde deve ser iniciado, à previsão das etapas a serem percorridas para atingir o objetivo almejado, relacionando as escolhas feitas em termos estratégicos.

Em uma atividade experimental, a planificação diz respeito ao planeja- 
mento que os estudantes fazem de suas ações, de modo a visualizar o fim desejado, detalhando e entendendo cada passo, verificando se dispõem do que precisam e retomando conhecimentos pertinentes à ação. Encontra-se vinculada ao "modo de fazer" ou ao procedimento para executar a atividade experimental. Assim, de posse da identificação do conhecimento que apresenta sobre o seu conhecimento, o estudante inicia o processo de execução e de autorregulação, planejando suas ações e organizando os passos que deverão guiar sua atividade a fim de atingir o objetivo pretendido.

A monitoração consiste em controlar a ação e verificar se ela está adequada para atingir o objetivo proposto, avaliando o desvio em relação a este, percebendo erros e corrigindo-os, se necessário. Brown (1987) destaca a importância de se monitorar ou revisar cada procedimento executado, reorganizando estratégias como forma de manter o rumo da ação. Flavell também destaca a importância da monitoração num processo metacognitivo, porém considera isso de forma mais abrangente, incluindo momentos de planejamento e de avaliação, vinculando-os a eventos cognitivos, como a recuperação da memória, por exemplo.

$\mathrm{Na}$ aprendizagem, a interpretação de Brown representa a revisão dos conhecimentos realizada pelos estudantes no momento em que estão construindo os novos conhecimentos, de modo a poderem avaliar se estão ou não no caminho certo para atingi-lo. Essas ações incluem, por exemplo, manter a atenção durante as explicações do professor, de modo a se questionarem permanentemente se estão ou não entendendo as explicações. De maneira geral, elas atuam como alerta aos estudantes sobre possíveis interrupções na construção do conhecimento ou na realização de uma atividade, permitindo que tomem decisões de mudanças a tempo.

Nas atividades experimentais, a monitoração encontra-se associada à ação dos estudantes em relação ao seu planejamento. Ela possibilita que o estudante se mantenha atento aos passos que estão sendo executados e à verificação quanto a haver coerência entre os conhecimentos envolvidos na atividade e os resultados obtidos, remetendo-os ao objetivo proposto. É o momento de refletirem sobre a ação e as decisões que estão sendo tomadas, esclarecendo os equívocos ou reforçando os acertos. Por exemplo, no momento em que os estudantes estão executando o procedimento em uma atividade experimental, se percebem que o valor encontrado está distorcido em relação aos demais, retomam a sua medição, ou, ao contrário, verificam a coerência de suas medidas; o que também acontece quando confrontam o valor encontrado com o discutido na teoria. Tudo isso representa momento de revisão da ação e de avaliação diante de seus conhecimentos e do objetivo pretendido, podendo representar um momento de evocação do pensamento metacognitivo.

A avaliação identifica-se com os resultados atingidos em face do fim visado, podendo ser definida, eventualmente, pelos critérios específicos de avaliação. No âmbito escolar, esse é o momento em que os estudantes retomam e avaliam a aprendizagem com o intuito de identificar como a realizaram. Esse momento pode servir para entender o processo de execução da atividade, o conhecimento dela decorrente, ou, ainda, para identificar possíveis falhas no processo. Nas ativi- 
dades experimentais, a avaliação encontra-se associada à etapa de conclusão, que, por sua vez, representa o momento final dessa atividade na qual são indicados os resultados obtidos. Porém, num processo metacognitivo, avaliar não se restringe apenas a registrar os resultados finais, mas envolve também confrontá-los com o objetivo pretendido, verificando possíveis equívocos e desvios, sejam operacionais ou conceituais. É também o momento de verificar se os estudantes entenderam a atividade desenvolvida e o conhecimento envolvido.

Os estudantes estão agindo de forma a permitir a evocação de seus pensamentos metacognitivos quando, ao chegar ao final de uma atividade, percebem, por exemplo, a coerência entre os resultados e o objetivo, e também quando se dão conta de que devem rever o executado de modo a identificar possíveis falhas na operação da atividade ou na interpretação de um determinado conhecimento. A percepção de um desvio de medida e sua posterior identificação, ou a coerência das explicações sobre o realizado, também representam momentos propícios a essa evocação.

A proximidade das operações, mencionada por Brown, para a leitura e interpretação de textos com as atividades experimentais de Física, conforme exemplificado, induz a se considerar tais operações como integrantes do conceito de metacognição assumido para este estudo. Portanto, o conceito de metacognição apoia-se no apresentado por Flavell, mas recorre ao proposto por Brown, ficando assim expresso: Metacognição é o conhecimento que o sujeito tem sobre seu conhecimento e a capacidade de regulação dada aos processos executivos, somada ao controle e à orquestração desses mecanismos. Nesse sentido, o conceito compreende duas componentes: o conhecimento do conhecimento e o controle executivo e autorregulador.

A definição assumida é a clássica de Flavell, entretanto, as componentes desse conceito é que estão sendo interpretadas à luz de distintos referenciais de pesquisa presentes na literatura. Para a componente conhecimento do conhecimento, estão sendo consideradas as variáveis apresentadas por Flavell e Wellman em seus estudos sobre memória (pessoa, tarefa e estratégia), ao passo que para o controle executivo e autorregulador são consideradas as operações executivas decorrentes do detalhamento de Brown nos estudos sobre leitura e interpretação de textos (planificação, monitoração e avaliação).

\section{CONSIDERAC̣ÕES FINAIS}

Os estudos dos psicólogos John Hurley Flavell, Henry M. Wellman e Ann Lise Brown, embora voltados, especificamente, para temas oriundos de suas áreas de formação (psicologia), mostraram-se passíveis de aproximações com as atividades experimentais, sob um olhar mais didático para a metacognição. Esse "beber em outra fonte" possibilitou extrapolar os limites já investigados e fazer novas aproximações, aventurando por horizontes ainda não explorados com as atividades experimentais, o que ocorreu igualmente com a metacognição.

A possibilidade de a metacognição atuar como mecanismo potencializador 
da aprendizagem em Física parece pertinente de ser considerada pelos professores do Ensino Médio, ultrapassando a visão costumeiramente presente de que as atividades experimentais são destinadas a "comprobações" ou "exercícios práticos". A pesquisa teórica apresentada fornece subsídios para que os professores organizem ações didáticas levando em consideração os elementos metacognitivos apontados neste estudo, cuja pertinência de aproximação foi explicitada ao longo do texto.

A metacognição, assim estabelecida, oferece aos estudantes a possibilidade de "aprender como aprender", repercutindo em uma habilidade individual para identificar, representar, planejar e avaliar determinado problema, que poderá ser uma situação de aprendizagem. Vale lembrar que o mecanismo de envolver o pensamento metacognitivo é apontado como o diferencial entre os estudantes experts e os novatos em Física, conforme destacado nos estudos de Chi e colaboradores (1982; 1989). A identificação, por parte dos estudantes, dos seus conhecimentos e, sobretudo, a tomada de consciência proporcionada pelo pensamento metacognitivo levam os estudantes considerados bem-sucedidos a dedicarem mais tempo ao pensar antes de agir. De fato, as pesquisas em psicologia cognitiva têm revelado que os avaliados como experts dedicam um tempo maior à identificação do problema ou da atividade proposta, diante dos seus esquemas de pensamento e da seleção da estratégia e da planificação necessárias para sua realização, em comparação aos considerados novatos, supostamente com dificuldades de aprendizagem.

Por fim, destaca-se que o presente estudo limita-se à proposta teórica de aproximação entre a metacognição e as atividades experimentais, carecendo de sua efetivação no contexto escolar, o que vem sendo realizado pelos autores deste estudo.

\section{REFERENCIAIS BIBLIOGRÁFICOS}

BROWN, Ann L. Theories of memory and the problems of development: activity, growth and knowledge. 1977. Disponível em: <http://www.eric.ed.gov/PDFS/ED144041.pdf>. Acesso em: 11 jun. 2007.

. Knowing when, where, and how to remember: a problem of metacognition. In: GLASER, Robert (Ed.). Advances in instructional psychology. Hillsdale, New Jersey: Lawrence Erlbaum Associates, 1978. v. 1. p. $77-165$.

. Metacognition, executive control, self-regulation, and other more mysterious mechanisms. In: WEINERT, Franz E.; KLUWE, Rainer H. (Eds.). Metacognition, motivation and understanding. Hillsdale, New Jersey: Lawrence Erlbaum Associates, 1987. p. 65-116.

CHI, Michelene T.; GLASER, Robert; REES, Ernest. Expertise in problem solving. In: STERNBERG, Robert J. (Ed.). Advances in the psychology of human intelligence. v. 1. Hilsdale, N.J.: Erlbaum, 1982. . et al. Self-explanations: How students study and use examples in learning to solve problems. Cognitive Science, v. 13, p. 145-182, 1989.

FLAVELL, John Hurley. First discussant's comments: what is memory development the development of? Human Development, n. 14, p. 272-278, 1971.

Metacognitive aspects of problem solving. In: RESNICK, Lauren B. (Ed.). The nature of intelligence. Hillsdale, New Jersey: Lawrence Erlbaum Associates, 1976. p. 231-236.

. Metacognition and cognitive monitoring: a new area of cognitive - developmental inquiry. American Psychologist, v. 34, n. 10, p. 906-911, 1979.

. Speculations about the nature and development of metacognition. In: WEINERT, Franz 
E.; KLUWE, Rainer H. (Eds.). Metacognition, motivation and understanding. Hillsdale, New Jersey: Lawrence Erlbaum Associates, 1987. p. 21-29.

.; WELLMAN, Henry M. Metamemory. In: KAIL, Robert V.; HAGEN, John W. (Eds.). Perspectives on the development of memory and cognition. Hillsdale, New Jersey: Lawrence Erlbaum Associates, 1977. p. 3-33.

.; MILLER, Patricia H.; MILLER, Scott A. Desenvolvimento cognitivo. Tradução de Cláudia Dornelles. 3. ed. Porto Alegre: Artes Médicas Sul, 1999.

PINHO-ALVES, Jose. Atividades experimentais: do método à prática construtivista. 2000. Tese

(Doutorado em Educação) - Universidade Federal de Santa Catarina, Florianópolis, 2000.

Data do Recebimento: 14/06/2011

Data de Aprovação: 11/01/2013

Data da Versão Final: 15/01/2013 
